\title{
Ética e Víolência na Teoria das Relações Internacionais: Uma Reflexão a Partir do 11 de Setembro
}

João P. Nogueira

"O poder é, de fato, a essência de todo governo, mas a violência não. A violência é, por natureza, instrumental; como todo meio, carece sempre de orientação e justificação pelos fins que persegue. $\mathrm{E}$ aquilo que requer justificação por outra coisa não pode ser essência de nada." Hannah Arendt, On Violence, 1970.

\section{Introdução}

A brutalidade e o horror da guerra total marcaram o nascimento da disciplina de Relações Internacionais. A reflexão sobre a relação entre nossa condição humana e os limites do uso da violência, contudo, já encontra na antigüidade clássica a contribuição eloqüente de Tucídides, para quem "a guerra é mestre da violência" (Tucídides,

CONTEXTO INTERNACIONAL Rio de Janeiro, vol. 25, nº 1, janeiro/junho 2003, pp. 81-102. 
1986). Na Guerra do Peloponeso Tucídides nos mostra como Atenienses e Espartanos tornam-se, com o acirramento do conflito, capazes de praticar crimes que atentam contra os princípios de justiça e prudência comuns no mundo helênico. A transformação da Atenas de Péricles no império brutal que conduziu as expedições contra Melos e Siracusa representa o começo do ocaso humilhante da época de ouro da Grécia antiga. Ao contrário do que nos dizem autores realistas de hoje, a obra de Tucídides é um exemplo de reflexão sobre a ética na política internacional e não um tratado sobre sua submissão às necessidades do poder. Ainda assim, o internacional continua a ser hoje, para muitos, o lugar onde a violência é empregada em escala global e com uma intensidade sem precedentes, sem qualquer regulação significativa. Ética e política nas relações internacionais aparecem separadas pelo fosso da violência sem justificativa a não ser o interesse do Estado, seja ele qual for. Este mantra realista informa o relativismo moral com o qual o uso da violência é tratado pelos autores clássicos da política internacional e por tantos "internacionalistas", em nosso esforço quotidiano para compreender os fenômenos extraordinários e assustadores do universo da anarquia.

Os atentados terroristas contra as torres gêmeas e o Pentágono provocaram um amplo debate sobre um leque diversificado de questões da política mundial atual, que vão desde as implicações da constatação da vulnerabilidade do território norte-americano a ataques armados até as repercussões do evento sobre a configuração da ordem internacional do pós-Guerra Fria. Por outro lado, as reações à tragédia revelaram uma dualidade comum nas análises tradicionais de política internacional, que combinam a condenação ao massacre de milhares de civis inocentes, sem propósito declarado, com uma análise das motivações e do significado daquele ato baseada na lógica da "power politics". Neste sentido, comentaristas tanto à direita como à esquerda do espectro ideológico coincidiram - em graus variados de intensidade - em seu repúdio ao terrorismo como forma de ação política, 
bem como em sua atribuição das causas do atentado a uma reação de grupos insatisfeitos com a política externa norte-americana para o Oriente Médio, ou, em termos mais gerais, com a hegemonia norte-americana na ordem mundial contemporânea. O impacto dos atos praticados em setembro de 2001 foi, portanto, medido a partir de suas consequiências para a posição e prestígio dos EUA no sistema internacional.

As divergências situaram-se, em contrapartida, na avaliação da resposta dos Estados Unidos e na condução da "guerra contra o terror", em particular sobre a ação armada contra o Afeganistão. Na medida em que as providências adotadas pela administração Bush para fazer frente à nova ameaça demonstraram, como se esperava, a plenitude da arrogância do poder norte-americano, o debate tendeu a polarizar-se entre posições que demonizam o terrorismo e quase todos os movimentos de resistência armada que se opõem à política dos EUA (quase sempre equiparados aos valores e instituições democráticas daquela sociedade); e aqueles que responsabilizam a superpotência pelo acirramento dos conflitos sociais e políticos no mundo e que descontam a barbaridade do terror de Bin Laden em função de seu resultado: o desnudamento da barbárie maior do "Império".

O enquadramento do ato terrorista na categoria do "mal" obedece a uma lógica maniqueísta que sugere não haver explicação racional para a violência que causou tanta destruição e morte. Desloca o terreno do confronto para um plano transcendental, onde se situa a batalha entre o bem e o mal (Klusmeyer e Suhrke, 2002). Este movimento permite deixar de lado a discussão sobre o contexto político do ataque e adotar medidas retaliatórias drásticas que prescindam de uma justificativa baseada em uma racionalização política da situação. Daí o recurso incisivo à noção de guerra justa no discurso do presidente dos EUA e de seus principais assessores. É interessante notar, contudo, que um maniqueísmo análogo pode ser encontrado em muitas das críticas veementes à política externa norte-americana que ilus- 
tram as explicações para o ataque terrorista bem como a crítica às medidas tomadas por aquele país em resposta ao atentado. Alguns comentaristas chegaram a afirmar que os acontecimentos do $11 \mathrm{de}$ setembro de 2001 refletem, além das qualidades do "bom estrategista" Bin Laden, a convicção dos povos não-ocidentais de que seu futuro depende da "erosão do poder norte-americano" (Ceceña e Sader, 2002:5). A qualidade dos discursos é a mesma: a violência substitui a política porque a radicalidade do conflito (existencial, cultural) nos coloca diante da alternativa única de eliminação do Outro como condição da própria sobrevivência ${ }^{1}$. A dualidade amigo/inimigo, expressa nestas visões de mundo, é, de acordo com Carl Schmitt, constitutiva da política e se manifesta nos momentos de luta pela sobrevivência - na guerra. Na política mundial deste início de século, a violência organizada por atores privados adquire proporções e estatuto de guerra e as redes globais substituem Estados como fonte de ameaça (Huysmans, 1998). Apesar das transformações na prática da guerra e nas identidades dos agentes, as perspectivas -tanto conservadoras como as críticas - que informam as análises do terror global na política mundial, continuam a afirmar uma ética estatista nos moldes Schmittianos. O argumento apresentado neste artigo afirma que a reprodução desta "ética da soberania" nos discursos contemporâneos sobre o internacional determina limites à reflexão sobre o uso da violência e sobre as possibilidades de discutir e deliberar sobre convenções internacionais que protejam a integridade de indivíduos e comunidades de sua incidência, seja sob a forma de guerra ou de ataques terroristas (Linklater, 2002) ${ }^{2}$.

O ponto de partida deste trabalho é a insatisfação com a as possibilidades oferecidas pelas teorias convencionais de relações internacionais para avaliar e analisar o uso corrente da violência na política mundial, seja por atores estatais quanto não-estatais. Os limites da teoria se expressam na separação entre ética e política operada, tradicionalmente, pelo realismo, mas de fato inscrita na "problemática da 
Ética e Violência na Teoria das Relações

Internacionais: Uma Reflexão a Partir do 11...

anarquia" constitutiva do campo de estudos de Relações Internacionais. Ao subsumir considerações de ordem ética e moral à razão política (considerada como esfera autônoma) as teorias dominantes limitam a análise dos problemas cada vez mais complexos que caracterizam a realidade internacional atual à compreensão das variáveis tradicionais de interesse e poder que motivam a conduta dos Estados.

Um exame não muito profundo da natureza dos conflitos internacionais nos últimos quinze anos é suficiente para afirmarmos que eles não se inserem na dinâmica inter-estatal que é objeto das teorias convencionais. Mais do que isso, a natureza desses conflitos coloca problemas teóricos cuja resposta é, necessariamente, ética. Não me refiro apenas às questões mais comumente discutidas por teorias normativas, como justiça distributiva e exclusão social, mas igualmente a questões que têm estado no topo da agenda internacional - seja das políticas externas das grandes potências seja de organizações internacionais - desde, pelo menos, a Guerra do Golfo: intervenção humanitária, conflitos étnicos, genocídio, colapso e reconstrução de Estados, padrões de legitimidade internacional; privatização da violência; terrorismo; tráfico de armas; destruição do meio-ambiente, para citar apenas os mais conhecidos (Frost, 1996). Em outras palavras, os temas centrais da agenda internacional suscitaram novos questionamentos teóricos na medida e que o seu tratamento do ponto de vista dos paradigmas tradicionais da disciplina mostrou-se insatisfatório: como explicar decisões de intervir em crises humanitárias quando interesses geopolíticos não estão presentes? Ou melhor, como tratar temas de segurança quando estes passam a ser articulados com a situação de direitos humanos numa região ou país? Como definir os meios adequados para reconstruir Estados através da ajuda internacional respeitando a autonomia cultural das nações em questão? Que grupos étnicos têm status político para negociar soluções de conflitos que não respeitam fronteiras? Como agir em regiões onde o Estado desapareceu, como a Somália e o Afeganistão? 
A realidade internacional é cada vez menos ordenada de acordo com a divisão entre o doméstico e o internacional que sustenta a separação entre decisões políticas e julgamentos éticos. Os ataques terroristas contra os EUA foram um sinal dramático do equívoco inerente nas representações tradicionais da política mundial. Na ausência de qualquer potência ou aliança militar capaz de desafiar a hegemonia da única superpotência, uma rede transnacional inspirada por uma interpretação fanatizada do Islã, e cuja liderança operava a partir do território de um Estado falido, colocou em evidência a origem peculiar e inesperada dos "perigos da anarquia" nos tempos atuais. A mudança na natureza das ameaças à sobrevivência de Estados, comunidades e indivíduos no contexto global atual recoloca o tema da ética com força porque sugere que o mundo construído pela regra da soberania não oferece respostas para pluralidade de modos de ser que povoam a vida social ou, em outras palavras, para a relação entre comunidade e diferença na esfera do internacional (Shapcott, 2001). As teorias de relações internacionais foram sempre essenciais para a determinar o lugar do Outro no mundo moderno, ou seja, sempre partiram de pressupostos e tiveram implicações éticas indispensáveis para a legitimidade do poder em nome do qual falavam (Walker, 1995).

Neste trabalho levanto algumas perguntas acerca das implicações do uso da violência através do terror global para a teoria das relações internacionais. Para tanto, faço um breve retrospecto dos antecedentes da discussão sobre ética internacional na disciplina, e em seguida levanto alguns dados sobre a privatização dos meios de violência na política mundial atual. A tendência à diversificação dos atores com acesso a meios de violência - não tão recente mas de maior intensidade nos últimos vinte anos - é considerada enquanto desafio para uma reflexão sobre ética internacional que, como veremos em seguida, é tradicionalmente realizada a partir da "moralidade dos Estados". A partir de uma crítica a esta perspectiva pretendo sugerir que as limita- 
ções do instrumental teórico que inspira muitas das análises do ataque de 11 de setembro nos impedem de pensar parâmetros de regulação do uso da violência na política internacional a partir de uma redefinição da relação entre ética e política. Tais limites não têm, insisto, apenas implicações morais. Eles colocam obstáculos a uma crítica coerente e efetiva à ação das grandes potências, bem como enfraquecem as estratégias de atores engajados na transformação da política mundial no sentido de sua democratização.

\section{O Uso da Violência na Tradição da Ética Internacional}

A noção de ética internacional é tradicionalmente marginalizada na reflexão sobre política internacional desde, ao menos, o pós-guerra quando a disciplina adquiriu estofo acadêmico e densidade teórica. Desde então, qualquer tentativa de teorização normativa das relações internacionais passou a ser criticada no quadro de referência da oposição entre idealismo e realismo, que adquiriu o estatuto de "grande debate" fundador da disciplina. Na verdade, como observa Hutchings (1999), a discussão sobre ética internacional tende a reproduzir a lógica da oposição entre idealismo e realismo, ao conceber moral e política enquanto esferas distintas do conhecimento da realidade, onde a moral aparece como um momento de avaliação de um evento ou prática previamente analisados sob o prisma da racionalidade política. Nesse sentido, a função da teoria normativa seria a de considerar em que medida o comportamento dos atores políticos se conforma com um corpo de princípios morais universais (ou não), definidos a partir de discussões no campo da filosofia.

Realistas clássicos, como Morgenthau e Kennan, tratam a relação entre moralidade e política desta forma. Reconhecem a importância e necessidade de conformar a ação política a princípios morais, ao 
mesmo tempo em que afirmam a trágica impossibilidade de fazê-lo no universo da política de poder. Na ausência de outra limitação efetiva à conduta predatória dos Estados que não a oposição de coalizões de poder equivalente, o papel de normas e regras na política internacional é marginal e sua observância, um risco para o estadista. Este tratamento não era, é claro, uma novidade. Buscava resgatar as máximas que orientaram a conduta dos estadistas bem-sucedidos dos séculos XVIII e XIX da crítica liberal dos anos do entreguerras. No contexto da Guerra Fria estas posições se fortaleceram na medida em que qualquer discussão sobre ética parecia vã, num quadro de oposição de sistemas sociais inspirados por idéias antagônicas sobre os princípios fundamentais de ordenamento do mundo. Por outro lado, a ameaça de destruição mútua pelas armas nucleares gerou um impasse nos esforços de limitar o uso da força e suas consequiências para o sistema internacional — um aspecto central da carta da Organização das Nações Unidas (ONU) - uma vez que mesmo a guerra defensiva, a única tolerada pelas normas elaboradas depois da Segunda Guerra mundial, implicaria na destruição não só dos Estados envolvidos como de parte considerável da comunidade de nações.

Nesse sentido, a marginalização da reflexão sobre ética produziu também o divórcio entre política e direito internacional, tão representativo da Guerra Fria, relegando este último a uma irrelevância nunca antes vista na história do moderno sistema de Estados. Ainda assim, o desafio de pensar formas de distinguir entre o uso legítimo e ilegítimo da força tornou-se cada vez mais dramático depois de 1945, quando as superpotências recorreram às formas mais variadas de "guerra suja", intervenções, golpes, etc. Os desastres do Vietnã e do Afeganistão, e as políticas dos EUA e da URSS em suas respectivas áreas de influência são emblemáticas deste período. Com o fim da Guerra Fria e a proliferação dos meios de violência em conflitos que envolvem grupos étnicos, grupos armados a serviço de organizações criminosas, terroristas, companhias de mercenários, guerrilhas, etc., 
a regulação da violência política tornou-se um ponto crítico da agenda internacional, como demonstra, por exemplo, o bem sucedido movimento para a criação do Tribunal Penal Internacional (Dillon, 1998).

A volta do tema da regulação da violência e, portanto, de uma ética do uso da força nas relações internacionais, é interessante por tratar-se de uma preocupação central das diferentes tradições de pensamento sobre ética internacional, desde Tucídides, passando por Agostinho, Tomás de Aquino, Grócio, Gentili, Kant, e tantos outros filósofos e juristas que influenciaram a teoria internacional. A superação da doutrina agostiniana da guerra justa, predominante na Idade Média, foi, como é sabido, fundamental no processo de constituição do sistema europeu de Estados modernos. A doutrina de Gentili, por exemplo, ao afirmar que não existe um padrão absoluto para estabelecer a justiça de uma guerra, contribuiu de forma decisiva para conferir uma igualdade de status aos beligerantes. Não se tratava mais de avaliar a justiça das motivações que levam Estados à guerra, uma vez que estes, como soberanos, passariam a ser considerados fonte legítima da decisão sobre o uso da força. A questão da justiça tornou-se contingente às relações entre os próprios Estados, e não determinada por critérios abstratos, estabelecidos fora dessa relação com base na religião. Isto não quer dizer que a tradição da guerra justa tenha desaparecido com as inovações do direito internacional moderno, mas antes que considerações de justiça passam a aplicar-se à condução da guerra e não a suas causas (Forsyth, 1992).

Para o argumento desenvolvido aqui, um aspecto da teoria do direito à guerra é particularmente relevante: sua legitimidade e justiça não estão limitadas à forma de sua condução, ou seja, aos meios (jus in bello), mas também, e talvez, principalmente, a quem a conduz. A tradição ética internacional, presente no direito internacional público, e também na concepção anárquica do sistema de Estados formulada pela teoria de relações internacionais, sustenta a centralidade do 
Estado como pessoa (de direito) e ator (político) porque, na origem, tratava-se de distinguir quem, dentre as diferentes formações políticas existentes na transição para o sistema moderno, teria o direito de declarar e, posteriormente, conduzir uma guerra. A posição de Gentili é clara:

"uma guerra genuína ou autêntica era definida como uma contenda pública livrada por uma autoridade soberana ou pública, por uma causa pública... o inimigo era aquele que possui um Estado, um senado, um tesouro, cidadãos unidos em harmonia, e alguma base para um tratado de paz" (Forsyth, 1992).

O corte com a tradição medieval é marcante. Na Idade Média, além da "guerra pública", entre soberanos cristãos, consideravam-se ainda como "estados de guerra" as "guerras Romanas", conduzidas sob a autoridade da Igreja contra os infiéis; e guerras feudais que envolviam membros da nobreza em disputas pelo controle de algum domínio ou título. No sistema europeu de Estados, ambas deixaram de ser consideradas "guerras" segundo os parâmetros que passaram a regular o uso legítimo da força. O estado de guerra implicava no reconhecimento da igualdade de status entre os beligerantes e da capacidade de ambos selarem um tratado de paz. As guerras contra infiéis estavam excluídas por não envolverem partes iguais (a religião deixara de ser um motivo justo para a guerra) e por serem guerras "totais" cujo objetivo era a destruição do adversário. As guerras feudais eram conflitos "internos" que passariam a ser tratados como jurisdição doméstica dos soberanos.

O controle do uso legítimo da violência pelo Estado soberano permitiu resolver, como vimos, uma questão ética e moral que durante séculos esteve sujeita às vicissitudes da doutrina da guerra justa. O interesse do soberano passou a servir como condição suficiente para a justiça de um conflito. Uma conseqüência importante desta mudança conceitual foi a exclusão de atores não-estatais do direito a defender causas "justas" através do uso da força. Como o estudo já clássico de 
Janice Thomson (1996) mostrou, os agentes militares privados (piratas, mercenários, companhias comerciais, etc.) passaram a servir, cada vez mais, aos Estados e foram, finalmente, colocados na ilegalidade no século XIX. Da mesma forma, o espaço para a ação política de atores não-estatais foi progressivamente reduzido na medida em que Estado moderno passou a controlar a regulação das esferas social, econômica e cultural das sociedades complexas. O declínio dos movimentos internacionalistas, tanto de inspiração liberal como socialista, ao longo do século XIX e seu desaparecimento no século $\mathrm{XX}$, reflete o triunfo do Estado como ator dominante e, depois da Segunda Guerra Mundial, universal da política mundial.

\section{A Privatização dos Meios de Violência}

O fim da Guerra Fria parece ter revelado que o processo de universalização do modelo do Estado-nação talvez tenha sido sobrestimado em sua robustez. Vários Estados pós-coloniais e pós-socialistas entraram em crises profundas de governabilidade; instabilidade política crônica; desorganização da economia; anomia social; fragmentação ou colapso. Contradizendo o conhecido refrão de Waltz, a taxa de mortalidade dos Estados já não podia ser considerada baixa. Não cabe analisar aqui os diversos fatores envolvidos nos processos de crise ou falência de Estados que se multiplicaram nos últimos quinze anos. O que nos interessa é chamar a atenção para o fato de que em grande parte dos países em que o Estado perde a capacidade de governar ou simplesmente desaparece, verifica-se a ação vigorosa de grupos armados irregulares, com acesso a recursos e armas obtidas normalmente através do tráfico internacional, e que passam a controlar regiões ou localidades sem oposição que qualquer autoridade pública.

O caso da Somália, por exemplo, é emblemático de como a falência do Estado dá lugar ao controle do território por milícias ligadas a clãs 
rivais $^{3}$. Mary Kaldor (1999:70), em seu livro sobre a política e a economia das "novas guerras", atribui suas causas a uma crescente "dissonância cultural" entre os que participam de redes transnacionais e aqueles excluídos dos processos globais e presos à uma dimensão local cada vez mais definida pelo poder daqueles que têm acesso aos recursos para operar naquelas redes. Seria uma simplificação dizer que as novas guerras constituem uma reação particularista à globalização. Como a análise de conflitos como o que assolou a Bósnia demonstra, o genocídio e a limpeza étnica foram perpetrados por grupos articulados, através de redes e canais de comunicação transnacionais, ao governo iugoslavo, a comunidades sérvias vivendo em diversos países da Europa, a organizações criminosas russas, ao sistema financeiro internacional, etc. Eram as vítimas das atrocidades que estavam isoladas e procuravam, a qualquer custo, comunicar-se com a "comunidade internacional" na tentativa de obter ajuda. No bojo dos atentados contra os EUA vários comentaristas salientaram, corretamente, que o fenômeno fundamentalista é eminentemente transnacional e independente de um Estado nacional em particular. O que ocorre, portanto, é um rompimento das "divisões socioeconômicas que definiram os padrões políticos do período moderno", fazendo com que conflitos que assumem formas tradicionais e se justificam em termos de valores enraizados no passado, sejam, de fato, fenômenos estritamente contemporâneos que não podem ser compreendidos fora do quadro de referência da globalização (Kaldor, 1999).

As novas guerras estão longe da noção de guerras públicas de Gentili e escapam, portanto, à regulação normativa pelos princípios do direito internacional ou da ética internacional clássica. Por isso, levantam questões difíceis para as teorias internacionais que tentam analisar sua natureza e informar políticas de resolução de conflitos e de "peacemaking". Como manter a paz e a segurança internacionais com os instrumentos do sistema de Estados quando a maior parte da violência é causada por atores que não se submetem a autoridade do 
Ética e Violência na Teoria das Relações

Internacionais: Uma Reflexão a Partir do 11...

Estado? Este é certamente um dos dilemas centrais da ONU desde o fim da Guerra Fria, bem como um problema prático de primeira ordem na ação das missões de paz em todo o globo uma vez que a organização está fundada no pressuposto da universalização do sistema de Estados e sua missão é preservá-lo contra "ameaças à paz e segurança internacionais" e reproduzi-lo através da defesa da regra da soberania. A Carta da ONU representa o ponto máximo das restrições da sociedade internacional à prática da guerra, que só é permitida por razões defensivas. Mas a guerra é considerada, ainda, como o confronto armado entre Estados. As novas guerras, por outro lado,

"se caracterizam por uma multiplicidade de tipos de unidades de combate, tanto públicas como privadas, estatais e não estatais[...]: exércitos regulares ou seus remanescentes; grupos paramilitares; unidades de auto-defesa; mercenários estrangeiros; e, grupos estrangeiros regulares sob auspício internacional" (Kaldor, 1999).

A esta lista podemos acrescentar outros protagonistas importantes que, se não atuam diretamente nas guerras de identidade, participam de forma mais ou menos determinante de sua dinâmica, bem como de outros conflitos de baixa intensidade: grupos terroristas, contrabandistas de armas, traficantes de drogas, agentes financeiros, organizações criminosas de diversos tipos. Como o envolvimento destes diferentes atores se dá de uma forma pouco transparente e muitas vezes sobreposta, é evidente que torna-se difícil distinguir entre a violência organizada com fins políticos que define a guerra, e a violência de bandos criminosos "comuns". De fato, predomina, nas guerras de identidade, o emprego de métodos brutais contra combatentes e não combatentes e multiplicam-se os crimes de guerra e contra a humanidade. Duas consequiências importantes para o argumento deste trabalho derivam desta fusão da violência política com a criminosa: primeiro, os esforços internacionais de imposição da paz e reconstrução de Estados tendem a sancionar os ganhos políticos obtidos através de atos violentos criminosos, reproduzindo assim a área cinzenta que envolve os tipos de violência empregados no conflito; segundo, 
acentua-se a tendência - em particular após o 11 de setembro - a criminalizar toda forma de violência política sob o rótulo do terror. A confusão permanece e os parâmetros éticos e jurídicos formulados para lidar com situações cada vez mais complexas ficam sujeitas às vicissitudes e circunstâncias das estratégias de combate e aos conceitos de segurança das grandes potências.

\section{Moralidade do Estado e - Ethos da Sobrevivência}

A teoria de Relações Internacionais, em suas versões convencionais, têm pouco a oferecer para a reflexão sobre os problemas referidos anteriormente. Ao tratar separadamente ação política e avaliação ética, oferece respostas ambíguas ou moralmente indigentes que não fornecem bases para decidir, por exemplo, intervir numa crise humanitária ou não: trata-se de um problema de segurança ou de uma defesa de princípios universais (direitos humanos)? Como a resposta a esta pergunta define os meios e o escopo de operações de paz, não é surpresa assistir à inadequação e ineficácia das ações internacionais na Somália, Kosovo, Ruanda, e tantos outros lugares que protagonizam as contradições dos tempos atuais.

A confortável dualidade entre moralidade e poder foi subvertida pela indefinição das linhas que separam o público e o privado, o doméstico e o internacional, o político e o criminoso, que, como vimos, caracteriza tantos conflitos nas relações internacionais do pós-Guerra Fria. Neste contexto, voltaram a fazer parte da discussão atual, por exemplo, os conceitos de guerra justa e de intervenção humanitária e, conseqüentemente, o debate teórico passa a ter que considerar suas implicações normativas (Rengger, 2002). Tradicionalmente tais questões foram tratadas sob a perspectiva da "moralidade dos Estados", ou seja, da consideração dos Estados como fonte de legitimidade e de autoridade ético-moral por excelência (Hutchings 1999). 
Ética e Violência na Teoria das Relações

Internacionais: Uma Reflexão a Partir do 11...

O estatuto privilegiado do Estado deriva, é claro, da regra da soberania que, na narrativa Hobbesiana, resulta do contrato social. A sobrevivência do Estado torna-se, assim, o principal objetivo da diplomacia e adquire um valor moral supremo na medida em que sua defesa é indispensável para a vida da comunidade política. A doutrina da moralidade do Estado permite justificar a mobilização de todos os recursos, inclusive o uso da força, para sua defesa, por razões moralmente justas, e superar as dificuldades do argumento realista crasso da defesa do interesse do Estado enquanto imperativo da ordem (Walzer, 1977). Por outro lado, a instituição da soberania circunscreve a vida política às fronteiras do Estado territorial, excluindo a possibilidade de existência de subjetividade fora da comunidade nacional. É com base neste fundamento epistemológico que o Estado adquire a condição de sujeito central das relações internacionais e que a ética internacional passa a ter como referência necessária para a reflexão sobre questões normativas a posição do Estado na sociedade internacional (Walker, 1995). Tornam-se evidentes, então, as razões pelas quais o Estado passou a ser o único agente com o direito de empregar a violência organizada para defender seus interesses. Tal monopólio visa dar condições aos Estados de garantirem sua sobrevivência, bem como regular o uso da força de modo a assegurar a continuidade da própria sociedade internacional - dois objetivos centrais da ordem internacional, segundo Bull (1982). Em outras palavras, a exclusão de agentes privados do privilégio de usar a força armada para defender seus interesses está articulada a uma dimensão constitutiva do sistema de Estados, quer seja, a delimitação do espaço político a partir do princípio da soberania.

A principal limitação da perspectiva da moralidade do Estado está em sua suposição de que é capaz de realizar a síntese do universal com o particular, ou seja, em reconciliar a separação e a diferença de indivíduos e comunidades através de sua participação numa sociedade internacional plural, constituída por Estados fundados num con- 
trato social que põe fim ao conflito crônico do estado de natureza. Bull se posiciona claramente ao afirmar que a sociedade anárquica não é capaz de realizar os ideais de justiça de uma comunidade maior de seres humanos, ao mesmo tempo em que afirma que tal sociedade representa o estágio mais avançado do desenvolvimento da espécie humana e que, portanto, deve ser preservada acima de qualquer outro objetivo ideal (utópico).

Contudo, como argumentamos desde o início, uma das questões centrais colocadas pelos processos em curso na política mundial é a disjunção entre identidades individuais e coletivas e as instituições políticas modernas, em particular o Estado-nação. A tensão entre o particular e o universal não é resolvida no e pelo Estado, mas antes acentuada por ele, produzindo conflitos e dinâmicas de fragmentação, colapso e formas perversas de violência. Uma vez que o Estado e seu estatuto ético-moral são colocados em questão apresenta-se, concomitantemente, um questionamento profundo da promessa de paz e segurança, para não falar de justiça, da sociedade internacional. As estratégias de reordenamento do sistema internacional têm se pautado pelo esforço, às vezes concertado, outras não, de combater a fragmentação através de intervenções e operações de reconstrução de Estados falidos. A complexidade do contexto faz com que as motivações dessas operações se articulem em termos objetivos de segurança regional ou coletiva, combinados com razões morais. A vinculação do comportamento dos Estados ao interesse nacional é cada vez mais indireta de difusa. As limitações de teorias internacionais fundadas numa "ética da sobrevivência" do Estado tornam-se, hoje, mais claras.

Fora do quadro de referência da "moralidade do Estado" correntes críticas na teoria de relações internacionais buscaram pensar o nexo entre reflexão ética e política a partir dos debates entre diversas posições cosmopolitas e comunitaristas na teoria política (Shapcott, 2001). A contribuição teórica destas perspectivas normativas é fun- 
damental para a compreensão dos dilemas políticos e morais colocados pela fratura entre o universal e o particular expressa na crise do Estado moderno. Para a política internacional, pensar suas transformações e conflitos e termos da relação entre indivíduos, comunidades particulares de toda natureza, Estados, organizações internacionais e a sociedade internacional como um todo requer, justamente, um quadro de referência que ultrapasse o ethos estatal. Da mesma forma, a regulação do emprego da violência organizada, capacidade hoje difusa entre os muitos atores da política mundial, deve ser discutida a partir da constatação empírica e da crítica teórica à noção de que o Estado - sua existência/sobrevivência - seja portador de um estatuto ético incontestável enquanto expressão da vida política de toda comunidade. O monopólio da violência organizada nas mãos do Estado se funda no "ethos da sobrevivência" gerado pela ontologia perigosa do mundo anárquico, um mundo onde só existem amigos ou inimigos. É a ameaça sempre iminente ao Estado que justifica a violência:

"A ameaça existencial colocada pelo inimigo priva a política de qualquer outra preocupação: a política não precisa justificar sua existência fazendo referência a outras preocupações. Justifica-se pela mera existência de uma ameaça existencial [...] É a continuidade da sobrevivência da coletividade que justifica, 'por sua mera existencial, a possibilidade de eliminação físi$\mathrm{ca}[. .$.$] é preciso notar que a sobrevivência não é meramente existencial mas$ ética" (Odysseos, 2002).

O "ethos da sobrevivência" confere, portanto, ao Estado o poder e controle sobre a maneira como nos relacionamos com "os outros lá fora" (Estados ou não). Nesse sentido, a violência do Estado contra qualquer inimigo encontra justificativa perene no imperativo da sobrevivência, mas contra o Estado apenas outro Estado pode, legitimamente, empregar a força, considerando as limitações colocadas pelas normas que regulam a atividade da guerra.

Ora, o dilema [ético] que vivenciamos hoje resulta da continuação do predomínio de leituras da política mundial referidas na ontologia do perigo característica da lógica anárquica, num contexto em que o 
Estado, sujeito central desta visão de mundo, não mais detém o estatuto ético ou empírico que lhe conferiu o direito exclusivo de lutar por sua sobrevivência (e por seus interesses) empregando todos os recursos necessários. Daí a criminalização de todas as outras formas de violência social e política - inclusive do terrorismo - e a impossibilidade conceitual de atribuir atos terroristas a Estados, mesmo que tais atos possam ser assim definidos em seus próprios termos (como, por exemplo, nos casos de emprego deliberado de violência em larga escala contra civis) ${ }^{4}$. Da mesma forma, a prevalência do ethos da sobrevivência nas leituras sobre a relação entre política e violência no sistema internacional inviabiliza a afirmação de uma ética que transcenda a dicotomia amigo/inimigo e, conseqüentemente, a possibilidade de uma crítica não pragmática do uso da violência. Somente nestes termos podemos postular uma condenação categórica ao terrorismo sem renunciar à crítica da ordem internacional existente.

Os atentados de setembro de 2001 representam a mais significativa expressão de emprego da violência contra um Estado soberano por um agente não-estatal na história do sistema internacional moderno. Esta constatação, por si mesma, deveria convidar ao debate sobre o estatuto do Estado soberano na política mundial hoje, bem como dos fundamentos éticos constitutivos do sistema internacional. Lamentavelmente, boa parte da discussão se concentrou na resposta norte-americana e suas conseqüências, circunscrevendo-a aos parâmetros convencionais da lógica da anarquia (Buzan, 2001). As condenações ao ato terrorista em si reproduziram, freqüentemente, a dualidade entre avaliação ética e análise política e caíram, inevitável e rapidamente, na irrelevância. Este trabalho pretendeu levantar algumas questões de maneira a contribuir para uma reflexão sobre os fundamentos éticos da economia da violência no mundo atual que, creio, é muito importante para o esforço mais amplo de reformulação da teoria de relações internacionais. 


\section{Notas}

1. Chomsky, por outro lado, se dissocia daqueles que interpretam um atentado como uma reação contra a globalização, o imperialismo ou a civilização ocidental, considerando tais críticas como superficiais e irrelevantes. Ver Chomsky (2002).

2. "Ao longo das décadas, os principais debates na área preocuparam-se em discutir se o mal, sob a forma da violência e da coerção, era uma característica inevitável de sistemas de estados e se sua erradicação seria possível apenas se a humanidade atingisse um consenso sobre princípios morais básicos, ou , se tudo o que podemos esperar é que os estados usarão a diplomacia, o direito internacional e as instituições para reduzir o sofrimento que causam uns aos outros." (Linklater, 2002:320).

3. Para uma discussão da crise do Estado na África, ver Zartman (1995).

4. Ver Chomsky (2002).

\section{Referências Bibliográficas}

BOOTH, K., DUNNE, T. et alii. (2000), "How Might We Live? Global Ethics in a New Century." Review of International Studies, vol. 26, Special Issue, pp. $1-28$.

BULL, H. (1982), The Anarchical Society: A Study of Order in World Politics. London, Macmillan.

BUZAN, B. (2002), "As Implicações do 11 de Setembro para o Estudo das Relações Internacionais”. Contexto Internacional, vol. 24, nº 2, pp. 233-263.

CECEÑA, A. E. e SADER, E. (2002), "Hegemonías y Emancipaciones: Desafios al Pensamiento Libertario", in Ana Esther Ceceña e Emir Sader (eds.), $L a$ Guerra Infinita: Hegemonia y Terror Mundial. Buenos Aires, CLACSO.

CHOMSKY, N. (2002), 11 de Setembro. Rio de Janeiro, Bertrand Brasil. 
João P. Nogueira

DILLON, M. (1998), “Criminalising Social and Political Violence Internationally”. Millennium: Journal of International Studies, vol. 27, $\mathrm{n}^{\circ}$ 3, pp. 543-567.

FORSYTH, M. (1992), “The Tradition of International Law”, in Terry Nardin e David R. Mapel (eds.), Traditions of International Ethics. Cambridge, Cambridge University Press.

FROST, M. (1996), Ethics in International Relations: A Constitutive Theory. Cambridge, Cambridge University Press.

HUTCHINGS, K. (1999), International Political Theory: Rethinking Ethics in a Global Era. London, Sage Publications.

HUYSMANS, J. (1998), “The Question of the Limit: Desecuritization and the Aesthetics of Horror in Political Realism”. Millennium: Journal of International Studies, vol. 27, nº 3, pp. 569-589.

KALDOR, M. (1999), New \& Old Wars: Organized Violence in a Global Era. Stanford, California, Stanford University Press.

KLUSMEYER, D. e SUHRKE, A. (2002), “Comprehending 'Evil'? Challenges for Law and Policy”. Ethics and International Affairs, vol. 16, nº 1, pp. 27-42.

LINKLATER, A. (2002), “The Problem of Harm in World Politics: Implications for the Sociology of States-Systems". International Affairs, vol. 78, nº 2, pp. 319-338.

ODYSSEOS, L. (2002), "Dangerous Ontologies: the Ethos of Survival and Ethical Theorizing in International Relations". Review of International Studies, vol. $28, \mathrm{n}^{\mathrm{o}} 2$, pp. 403-418.

RENGGER, N. (2002), “On the Just War Tradition in the Twenty-First Century”. International Affairs, vol. 78, nํㅡㄹ pp.353-363.

SHAPCOTT, R. (2001), Justice, Community, and Dialogue in International Relations. Cambridge, Cambridge University Press.

TUCÍDIDES. (1986), História da Guerra do Peloponeso. Brasília, Editora Universidade de Brasília.

WALKER, R. B. J. (1995), "International Relations and the Concept of the Political”, in Ken Booth e Steve Smith (eds.), International Relations Theory Today. University Park, Pennsylvania State University Press. 
Ética e Violência na Teoria das Relações

Internacionais: Uma Reflexão a Partir do 11..

WALZER, M. (1977), Just and Unjust Wars: A Moral Argument with Historical Illustrations. New York, Basic Books.

ZARTMAN, W. (ed.). (1995), Collapsed States. The Disintegration and Restoration of Legitimate Authority. Boulder, Lynne Rienner Publishers.

\section{Resumo}

\section{Ética e Violência na Teoria das Relações Internacionais: Uma Reflexão a Partir do 11 de Setembro}

Os atentados de setembro de 2001 representaram a mais significativa expressão de emprego da violência contra um estado soberano por um agente não-estatal na história do sistema internacional moderno. Esta constatação, por si mesma, deveria convidar ao debate sobre o estatuto do estado soberano na política mundial hoje, bem como dos fundamentos éticos constitutivos do sistema internacional. Lamentavelmente, boa parte da discussão se concentrou na resposta norte-americana e suas conseqüências, circunscrevendo-a aos parâmetros convencionais da lógica da anarquia. As condenações ao ato terrorista em si reproduziram, freqüentemente, a dualidade entre avaliação ética e análise política e caíram, inevitável e rapidamente, na irrelevância. Este trabalho levanta algumas questões sobre o uso da força na política internacional, de maneira a contribuir para uma reflexão sobre os fundamentos éticos da economia da violência no mundo, como parte de um esforço mais amplo de reformulação da teoria de relações internacionais.

Palavras-chave: Violência — Terrorismo - Teoria das Relações Internacionais - Ética — Soberania 
Abstract

\section{Ethics and Violence in International Relations Theory: Considerations After September 11}

The attacks of September 2001 were the most significant instance of the use of force by a non-state agent against a sovereign state in the history of the modern international system. An event of such significance should, in itself, stimulate further discussion about the standing of states in world politics, as wells as on the ethical foundations of today's international system. Unfortunately, most debates have focused on the US response to the attacks and their consequences, circumscribed by the conventional standards of the logic of anarchy. Condemnations of the attacks have often reproduced the duality between ethical considerations and political analysis. This work raises some questions about the use of force in world politics in an attempt to contribute to a discussion about the ethical basis of the economy of violence today.

Key words: Violence - Terrorism - International Relations Theory Ethics - sovereignty 